\title{
The current account sustainability of European transition economies
}

\author{
Juan Carlos Cuestas \\ University of Sheffield
}

\begin{abstract}
This paper analyses the sustainability of the current accounts of a group of Central and Eastern European countries. Given the link between national savings (public and private) and investment, the current account may yield instabilities in fundamental macroeconomic variables. Hence, this analysis is of paramount importance given the 2008-2011 debt crises faced by many European economies, and the addition of new countries to the Economic and Monetary Union. By means of unit root tests and fractional integration it is shown that, in general, the ratio of the current account to gross domestic product is a stationary and mean reverting process. However, in some cases shocks tend to have long lasting effects, implying that there is no evidence of a potential debt default in this group of countries.
\end{abstract}

J.E.L. Classification: C32, E24

Key words: Unit roots, fractional integration, current account, EU.

Acknowledgments: The author gratefully acknowledges Rob Ackrill, Barry Harrison, Miguel A. León-Ledesma, Nikhil Masters, Kostas Mouratidis and Karl Taylor, and two anonymous referees for comments on an earlier draft. The usual disclaimer applies. The financial support of the MICINN (Ministerio de Ciencia e Innovación, Spain) research grant ECO2011-30260-C03-01 is also acknowledged. 


\section{Introduction}

The analysis of current account deficits and their sustainability has gathered momentum since the 2008-2010 financial crisis. Fears of countries defaulting on their external debt have increased during the last few years after some European countries have shown relatively high rates on both internal and external debt. The flow of funds approach, from basic macroeconomic theory, predicts that net exports should equal public saving plus private saving net of investment. Hence, there is an important connection between external and internal debt.

A popular approach to analysing the degree of persistence in the current account deficit and therefore whether a current account is sustainable, is the use of unit root and stationarity tests (see Coakley et al., 1996, Milessi-Ferretti and Razon, 1996, and Taylor, 2002, for example). If shocks have transitory effects, the current account is a stationary process and external debt is mean reverting. In this situation, according to Trehan and Walsh (1991) and Husted (1992), the country is solvent and therefore these are necessary conditions for sustainability. Hence, if the current account balance is mean reverting and stationary, external debt will not grow forever after a shock. In a recent but seminal contribution, Bohn (2007) provides evidence that stationarity is not necessary for the transversality condition, derived from the inter-temporal budget constraint, to hold. Still, the external deficit may satisfy the transversality condition for higher orders of integration than zero. However, the time series properties of the current account are quite informative. Policy makers may want to learn when and how current account mean reversion happens. Within the literature, stationarity of the current account balance over GDP is seen as a strong form of sustainability.

If shocks have permanent effects, external debt is a unit root process, and may even be explosive so that external debt will not revert to equilibrium after a shock. In this situation, deficits tend to increase in the long run and the application of economic reforms will be necessary to avoid a situation of excessive debt accumulation. Indeed, reform may also be necessary when the process 
is not stationary, but mean reverting, when the speed of mean reversion is relatively slow. Such considerations are particularly important for European transition economies, in particular those Central and Eastern European Countries (CEECs) which are candidates, or even have aspirations, to join the Eurozone (see section 2 for more details).

There is a much smaller literature on the analysis of current account sustainability for recently emerged economies than for industrial economies (Holmes, 2006). For CEECs Holmes (2004) finds evidence of current account sustainability for some, by means of applying (linear) unit root tests to panel data, in contrast to the general findings of studies looking at industrialised countries (Holmes, 2006, Stein, 2007, and Christopoulos and León-Ledesma, 2010, and Cunado, Gil-Alana and Pérez de Gracia, 2010).

This paper follows the approach of Christopoulos and León-Ledesma (2010), who apply nonlinear unit root tests to test for current account sustainability (their application was to the US). In addition this paper also uses panel unit root tests in order to gain power by taking into account cross-sectional information. Finally, in order to gain some flexibility when analysing the order of integration of variables (Gil-Alana and Robinson, 1997, amongst others), the Robinson (1995) test for fractional integration is also applied.

The remainder of the paper is organised as follows. The second section discusses the issue of current account sustainability for CEE countries. Section three explains the methods applied to analyse current account sustainability and the fourth and fifth sections present the results and concluding remarks, respectively. 


\section{Current account sustainability and Central and Eastern Europe}

As pointed out by Roubini and Wachtel (1999), current account deficits are of particular importance for transition economies, given the general upward trend in the real value of their currencies. With an appreciating real exchange rate and currency boards, like the ones maintained by most CEECs, this may destabilise the current account even more.

The reasons for analysing the current account sustainability are, then, twofold. First, the current account balance could be considered a proxy for the strength of the external position of the country since it is a measure of the foreign resources that come into the country to finance insufficient national savings. Second, the degree of persistence of current account deficits provides insights into the possibility that countries might default. Temporary or transitory current account deficits may promote economic growth, as far as they are allocated in countries to productive investments. However, permanent deficits might imply increasing interest repayments and this may impose restrictions on future generations, and/or, eventually, the impossibility of ultimate redemption of debt. In this situation, a short term solution is the application of a tight monetary policy in order to increase national interest rates to attract foreign capital. This, of course, will affect real exchange rates and the overall competitiveness of the country, reducing the current account. However, these measures increase the cost of debt and, to the extent that this happens, debt repayment will be even more difficult for the host country (see Christopoulos and León-Ledesma, 2010, amongst others). Also, this will increase the overall fiscal debt burden, increasing internal debt problems which many European countries are already facing.

This situation will not be very promising especially for those EU countries which joined the Union without an opt-out clause, and who will therefore have to join the Economic and Monetary Union in the future. This implies satisfying the Maastricht criteria on public debt, interest rates, exchange rates and inflation differentials with the best three EU inflation performers. In particular, 
the Maastricht Treaty states that the country should be in the Exchange Rate Mechanism II for two years without friction, which means no possibility of devaluation whatsoever. If countries run large and permanent current account deficits, devaluation of the currency could otherwise be a feasible option to increase competitiveness. This downward pressure over the value of a country's currency might provoke speculative attacks. To date, Estonia, Slovakia and Slovenia have become members of the Economic and Monetary Union and have adopted the single currency as a unique legal currency. For these economies the possibility of devaluation is non-existent, and hence, the reduction of persistent current account deficits would have to rely on structural measures.

\section{Econometric methods}

The econometric approach is to apply a number of unit root tests for panel data, individual series and fractional integration in order to analyse the long run behaviour of the current account ratio to GDP for a pool of CEECs.

First, a group of panel unit root tests are applied. These tests take into account cross-sectional information, although is not possible to distinguish which series are $\mathrm{I}(0)$ when the null is rejected. Thus, in this paper the Levin, Lin and Chu (2002) (LLC), Im, Pesaran and Shin (2003) (IPS), Maddala and Wu (1999) and Choi (2001) (MWC) tests are applied. The first test imposes a common unit root under the null hypothesis, against the alternative of stationarity of all individual series, whereas the latter allow for individual stationarity under the alternative hypothesis. This supposes a less restrictive framework as, in the former case, the assumption of a common unit root under the null, or general stationarity under the alternative, may be too strong. Hence, IPS base their test on the assumption of different autoregressive parameters for each individual series.

An alternative approach is taken by MWC, who combine the different p-values of the individual auxiliary regressions, either for the ADF and Phillips-Perron tests, to obtain the following Fisher 
(1932)-type test,

$$
-2 \sum_{i=1}^{N} \ln p_{i} \rightarrow \chi_{2 N}^{2}
$$

where $p_{i}$ is the asymptotic p-value of a unit root test for individual $i$.

Finally, it is also possible to apply the Kwiatkowski et al. (1992) (KPSS) test in a panel framework. Thus, Hadri's (2000) test is a panel version of the stationarity test KPSS. Therefore, for the Hadri (2000) test, the null hypothesis is stationarity of all the individual countries of the panel.

In order to analyse the order of integration of the ratio of current account to GDP for the individual countries, two groups of unit root tests are also considered: Ng and Perron (2001), which are based on linear models, and Kapetanios, Shin and Snell (2003) (KSS) and Sollis (2009), which are nonlinear. This paper uses linear unit root tests as a starting point and benchmark for the subsequent analysis. However, because the assumption of constant parameters might be too simplistic, in this paper it is also taken into consideration the possibility of changing parameters. Unlike models with structural breaks, which normally depend on some historical incident which changes permanently the mean or the slope of the relations investigated, here it is incorporated the possibility of changing autoregressive parameters, depending upon the size of shocks. In general, small shocks, which may only have mild effects on a given economic variable, are unlikely to trigger any alarm and the national authorities may decide not to act to correct for any deviations. Nevertheless, when shocks are significant in nature and have an important effect on the target variable, the responsible authority may put in place a series of mechanisms and policy adjustment aimed at neutralising the effects of the shocks. In this situation, we may observe that the further the variable deviates from the equilibrium value, the faster will be the reversion towards it. This relaxation of the constancy of parameters implies that the autoregressive parameter in auxiliary regressions for unit root tests should depend on the values of the so-called transition variable which in general is a lag of the variable of interest. 
As previously mentioned, this type of state-dependent model should not be confused with models including structural breaks which, although a type of nonlinear model, the nonlinearity in the latter is related to the deterministic component, and not to the speed of adjustment towards equilibrium. Neglecting these sources of parameter inconstancy, when testing for unit roots, has been reported to affect the power of the tests (see KSS amongst many others). If the underlying data generation is nonlinear, linear unit root tests may confuse a stationary process with a unit root when the nonlinearity is not accounted for. In the case of this paper, let us suppose an inner regime and an outer regime where the ratio of current account to GDP may behave in a different manner.

According to the literature, nonlinearities may be relevant for analysing the time series properties of the current account; Milesi-Ferretti and Razin (1998) study declines in current account deficits and exchange rate depreciations in a number of low and middle income countries. They find the existence of some domestic factors which may trigger current account reversals. In addition, Freund (2000) finds that current account reversal is a function of the business cycle, and that there is a threshold (5\% of GDP deficit) which triggers reversion of current account, for a number of industrialised countries. Finally, Mann (2002) analyses the fundamentals of US current account reductions, arguing that the speed of mean reversion may be faster if investors adjust their portfolios. This may be done by means of reducing their holdings of US assets and a depreciating dollar able to equilibrate imports and exports ${ }^{1}$. Above all, these works highlight the importance of nonlinearities in the process of adjustment, which needs to be accounted for.

In addition, in this article it is also applied the KSS test. KSS developed a test which has under the null a unit root process, but unlike the linear unit root tests takes into consideration the possibility of a globally stationary exponential smooth transition autoregressive (ESTAR) process under the alternative hypothesis. This makes it possible to characterise the target variable as a two

\footnotetext{
${ }^{1}$ See also Holmes and Panagiotidis (2009) for nonlinearities in the context of cointegration for the US current account deficit.
} 
regime process, for which the change in regimes is smooth rather than sudden ${ }^{2}$. Therefore, the variable may behave as a stationary process in the outer regime, but as a unit root in the inner regime. The unit root hypothesis can be tested against the alternative of a globally stationary ESTAR process using the following auxiliary regression:

$$
\Delta y_{t}=\gamma y_{t-1}\left(1-\exp \left\{-\theta y_{t-1}^{2}\right\}\right)+\varepsilon_{t}
$$

The null hypothesis $H_{0}: \theta=0$ that the process is a unit root in the outer regime is then tested against the alternative $H_{1}: \theta>0$ of stationarity. However, this test cannot be performed directly over $\theta$, given that it is not possible to identify this parameter under the null hypothesis of random walk. By means of a first order Taylor expansion of (2), KSS propose the form:

$$
\Delta y_{t}=\beta y_{t-1}^{3}+e r r o r
$$

Testing $H_{0}: \beta=0$ against $H_{1}: \beta<0$ is equivalent to testing for unit roots in the outer regime. Equation (3) may incorporate lagged $\Delta y_{t}$. KSS consider three possibilities regarding the deterministic components in their test: applying the test to the raw data, to the demeaned data and to the demeaned and detrended data. Since we are analysing the ratio of the current account to GDP against convergence to an equilibrium value, the KSS test is applied to the demeaned data.

The nonlinear function used by KSS in order to take into account nonlinearities, assumes that shocks have symmetric effects upon the variable, that is, the sign of the shocks does not matter, only the size. However, for many economic variables this assumption may be too simplistic. The speed of mean reversion may actually depend not only on the absolute deviation from the

\footnotetext{
${ }^{2}$ Note that this type of smooth transition models nests other type of threshold autoregressive models.
} 
equilibrium, but also upon the sign of the shock. Intuitively, it makes sense to think that a negative shock on the current account balance may be more difficult to tackle than a positive shock. Hence, Sollis (2009) proposes a similar test to KSS, in the sense that both assume that the speed of mean reversion depends on deviations from equilibrium. However, Sollis (2009) distinguishes asymmetric or symmetric effects under the alternative hypothesis. This asymmetric ESTAR model (AESTAR) is defined as:

$$
\Delta y_{t}=G_{t}\left(\gamma_{1}, y_{t-1}\right)\left\{S_{t}\left(\gamma_{2}, y_{t-1}\right) \rho_{1}+\left(1-S_{t}\left(\gamma_{2}, y_{t-1}\right)\right) \rho_{2}\right\} y_{t-1}+\varepsilon_{t}
$$

where $G_{t}\left(\gamma_{1}, y_{t-1}\right)=1-\exp \left(-\gamma_{1}\left(y_{t-1}^{2}\right)\right)$, with $\gamma_{1} \geq 0$, and $S_{t}\left(\gamma_{2}, y_{t-1}\right)=\left\{1+\exp \left(-\gamma_{2} y_{t-1}\right)\right\}^{-1}$, with $\gamma_{2} \geq 0$. Again, equation (4) may incorporate lags of the dependent variable to control for autocorrelation.

Hence, the null hypothesis of a unit root can be specified as $H_{0}: \gamma_{1}=0$. However, under the null hypothesis, $\gamma_{2}, \rho_{1}$ and $\rho_{2}$ cannot be identified. To solve this problem Sollis (2009) proposes the use of the following auxiliary equation using Taylor approximations,

$$
\Delta y_{t}=\beta_{1} y_{t-1}^{3}+\beta_{2} y_{t-1}^{4}+\text { error }
$$

Thus, testing for unit roots in model (5) implies testing $H_{0}: \beta_{1}=\beta_{2}=0$ by means of an F-typetest, whose critical values are given by Sollis $(2009$, p. 121), since the standard F distribution is not valid for an unknown order of integration of the residuals in (5). If the null hypothesis is rejected, the possibility of symmetric vs. asymmetric shocks may be of relevance. Thus, this latter hypothesis can be tested by means of standard hypotheses testing, since the null of symmetry would 
imply that $\beta_{2}$ is not statistically significant.

In order to take into account the possibility of a slow speed of mean reversion towards equilibrium, in this paper it is also tested for the possibility of fractional orders of integration (see Diebold and Rudebusch, 1991, Hassler and Wolters, 1994, and Lee and Schmidt, 1996, for the analysis of power of unit root tests in the context of fractional integration). The aforementioned unit root tests only consider integer numbers for the order of integration, say $d$, which may be too restrictive, in particular when the variable requires a long period of time to revert to its mean. Following the contributions in the field of spectral analysis, long memory and fractional integration, the tests of Robinson (1995), which take into account the possibility of values of $d$ in the interval $(0,1)$ or even above 1 , is also used. The Robinson's (1995) method is based upon the original idea of Geweke and Porter-Hudak (1983) using a log-periodogram-type regression. It estimates the value of $d$ in:

$$
(1-L)^{d} x_{t}=\varepsilon_{t}, \quad t=1, \ldots T
$$

where $L$ is the lag operator and $\varepsilon_{t}$ is $I(0)$, without taking into consideration any AR or MA structure $^{3}$. The closer is the parameter $d$ to 1 , the more persistent is the process, and the effect of shocks on the variable will last longer. If $d \in(0,0.5)$ the series is covariance stationary and mean reverting. However, if $d \in[0.5,1)$ the series is no longer stationary, but still mean reverting. The case when $d \geq 1$ implies that the series is non-stationary and non-mean reverting.

Robinson (1995) proposes a multivariate semiparametric approach in order to estimate the differencing parameter $d$ in equation (6). This test may be applied to individual series or to a pool of variables; allowing in the latter, intercept and slope to be different for each individual of the

\footnotetext{
${ }^{3}$ Extensions of this approach have been examined by Moulines and Soulier (1999), Velasco (2000), Phillips and Shimotsu (2002) and Andrews and Guggenberger (2003), amongst others.
} 
pool.

\section{Empirical evidence}

The variable of interest for the current analysis is the ratio of the current account to GDP. The data for this empirical analysis have been obtained from Eurostat. Quarterly data have been used, from 1999:Q1 to 2011:Q3. The data have been seasonally adjusted using the X-12 filter. Figure 1 displays the ratios for the target countries. It appears that the deficits have been quite close to zero for most of the sample for countries like Bulgaria, Lithuania, Slovakia and Slovenia. However, this changed at the end of 2006 with the beginning of the global economic crisis. Figure 1 also shows that the deficits have improved at the end of the sample. As pointed out by Aristovnik (2006), the current account deficits for most of these countries are a result of long term growth, structural, external and domestic policy factors. In particular, the growth in trade deficits of merchandise products, slowdown in services trade, profit repatriation, and appreciation of the exchange rate.

The results from the panel unit root tests reported in Table 1 are rather mixed. Applying the LLC, IPS and ADF test on the raw data, the null of a common unit root cannot be rejected. In contrast, the Phillips-Perron and Hadri tests point to the existence of stationarity in the data. Using the cross sectional demeaned data in order to take into account cross section dependence ${ }^{4}$, the results are similar, with some evidence towards the alternative hypothesis at the $10 \%$ significance level when applying the IPS test.

In order to distinguish which countries' ratios are stationary, Table 2 reports the Ng-Perron, KSS

\footnotetext{
${ }^{4}$ In order to address sectional dependence, Pesaran (2007) proposes to expand the usual ADF auxiliary regression incorporating the lagged cross-sectional mean and its first difference, so as to get,
}

$$
\Delta y_{i t}=\alpha_{i}+\rho_{i}^{*} y_{i, t-1}+d_{0} \bar{y}_{t-1}+\sum_{j=0}^{p} d_{j+1} \Delta \bar{y}_{t-j}+\sum_{k=1}^{p} c_{k} \Delta y_{i, t-k}+\varepsilon_{i t}
$$

where $\bar{y}_{t}$ is the mean at time $t$ of all observations. 
and Sollis (2009) unit root tests results. These do not seem very promising. The null of a unit root can only be rejected at the 5\% significance level for the Czech Republic, Estonia and Lithuania. Some evidence of rejection of the null is found in the case of Latvia with the $\mathrm{Ng}$ and Perron tests at the $10 \%$ level. In addition, for the Czech Republic and Lithuania the null of asymmetric effect is rejected.

As mentioned, unit root tests may not be able to distinguish between unit root processes and fractional integrated processes. Thus, Table 3 displays the Robinson (1995) pooled test, for fractional integration. Interestingly, the null hypothesis that $d=0$, cannot be rejected in any case at conventional significance levels, and the estimated $d$ are below 1 . Therefore, the ratio of current account to GDP turns out to be a mean reverting process. This means that after a shock, the ratio tends to correct the effect of the shock and returns to the long run equilibrium. From Table 3 , it can be seen that the speed of mean reversion is different for each country, given that the estimated $d$ differs from country to country. However, in order to take into account the possibility of a more general model, autoregressive, fractionally integrated, moving average ARFIMA models are estimated for the target countries. $\operatorname{ARFIMA}(p, d, q)$ models take the form:

$$
\Phi_{p}(L)(1-L)^{d} x_{t}=\Theta_{q}(L) \varepsilon_{t}, \quad t=1, \ldots T,
$$

where $\Phi_{p}(L)$ and $\Theta_{q}(L)$ are polynomials of orders $p$ and $q$ respectively, with all zeros of $\Phi_{p}(L)$ outside the unit circle, and all zeros of $\Theta_{q}(L)$ outside or on the unit circle, and $\varepsilon_{t}$ a white noise process (Granger and Joyeux, 1980; Granger, 1980, 1981; Hosking, 1981). This has been done by means of using the Fox and Taqqu (1986) approach. The results are presented in Table 4. For all countries, an ARFIMA $(4, d, 0)$ seems to be the most appropriate model, except for Poland, where the selected model is an ARFIMA $(1, d, 0)$. The selection of the model has been made according to the 
Akaike information criterion. Again, the results point to different degrees of persistence, and in most cases the variables seem to be mean reverting, except in the cases of Romania and Hungary. This is corroborated by the impulse-response functions, obtained by means of Gourieroux and Monfort's (1997, p. 438) theorem, which are displayed in Figure 2. In general the variables show a high degree of persistence after a shock, although some interesting distinctions can be made. First, Slovakia and Slovenia tend to suffer less after a shock since the immediate effects are not very large, and the effects of the shock tend to vanish relatively quickly. Bulgaria, Estonia and Latvia, seem to suffer a huge impact immediately after the initial shock and, although the speed of mean reversion seems to be quite rapid, it takes a significant number of periods for the effects to disappear. The Czech Republic, Poland and Lithuania, only seem to suffer mild effects immediately after a shock, although the speed of mean reversion tends to be slow. Finally, Hungary and Romania do not seem to present mean reversion at all.

Interestingly, Slovakia and Slovenia are the countries which joined the Eurozone first from these countries, namely in 2009 and 2007. Looking at the evolution of their current accounts as a percentage of their GDP, in Figure 1, the results are not surprising since they are the countries with the most equilibrated current account in the region, probably linked to their examination for euro membership.

Some of the target countries have been in the Exchange Rate Mechanism II in order to fulfil this element of the Maastricht criteria. Given that Eurozone countries are their main trading partners, joining the single currency and losing the possibility of devaluation or revaluation will not help to correct current account deficits. This implies, therefore, that additional and, probably, more demanding policy decisions will need to be taken to reduce future current account deficits. This problem is particularly important for those countries which tend to suffer more severely from the effects of shocks on their current accounts.

In general it is found that, although the degree of persistence varies from country to country, 
with the exception of Hungary and Romania there is no statistical evidence indicating a potential problem of current account sustainability in this group of CEECs investigated. This result contrasts with previous studies on industrialised economies (Cunado et al., 2010, for instance) and complements those of Holmes (2004). The macroeconomic adjustments performed during the last decades by this group of countries, from communism to market economies in order to prepare for EU membership, have helped to control external debt.

\section{Conclusions}

This paper has provided evidence on the degree of sustainability of current account deficits for a pool of CEECs. This has been achieved by testing for the order of integration of the ratio of the current account to GDP, using a number of unit root and fractional integration tests. Although the results of the unit root tests indicate that shocks have permanent effects in the majority of the target countries, the fractional integration analysis provides more promising results, given that the variable appears to be stationary and mean reverting, in most cases. This result has important implications for policy modelling and for the future of an extended Eurozone, as shocks tend to die out in the long run, in these countries. 


\section{References}

Andrews, D.W.K. and P. Guggenberger (2003): "A bias-reduced log-periodogram regression estimator for the long memory parameter”, Econometrica, vol. 71, pp. 675-712.

Aristovnik, A. (2006): “Current account deficit sustainability in selected transition economies", $Z b$. Rad. Ekon. Fak. Rij., vol. 24, pp. 81-102.

Bhargava, A. (1986): "On the theory of testing for unit roots in observed time series", Review of Economics Studies, vol. 53, pp. 369-384.

Bohn, H. (2007): "Are stationarity and cointegration restrictions really necessary for the intertemporal budget constraint?”, Journal of Monetary Economics, vol. 54, pp. 1837-1847.

Christopoulos, D. and M. A. León-Ledesma (2010): “Current account sustainability in the US: What did we really know about it?", Journal of International Money and Finance, vol. 29, pp. 442-459.

Choi, I. (2001): "Unit root tests for panel data", Journal of International Money and Finance, vol. 20, pp. 249-272.

Coakley, J. F., F. Kulasi and R. Smith (1996): "Current account solvency and the Feldstein-Horioka puzzle”, Economic Journal, vol. 106, pp. 620-627.

Cunado, J., L. A. Gil-Alana and F. Pérez de Gracia (2010): "European current account sustainabilty: New evidence based on unit roots and fractional integration", Eastern Economic Journal, vol. 36, pp. 177-187.

Diebold, F.X., and G. D. Rudebusch (1991): "On the power of Dickey-Fuller test against fractional alternatives", Economics Letters, vol. 35, pp. 155-160.

Elliot, G., T. J. Rothenberg and J. H. Stock (1996): "Efficient tests for an autoregressive unit root", Econometrica, vol. 64, pp. 813-836.

Fox, R. and M. S. Taqqu (1986) "Large-Sample Properties of Parameter Estimates from Strongly Dependent Stationary Gaussian Time Series” The Annals of Statistics, vol. 14, pp. 517-532.

Freund, C. L. (2000): “Current account adjustment in industrialized countries", Board of Governors of the Federal Reserve System. International Finance Discussion Papers 692.

Fisher, R. A. (1932). Statistical Methods for Research Workers, 4th Edition, Edinburgh: Oliver \& Boyd.

Geweke, J. and S. Porter-Hudak (1983): "The estimation and application of long memory time series models", Journal of Time Series Analysis, vol. 4, pp. 221-237.

Gil-Alana, L. A. and P. Robinson (1997): "Testing of unit root and other nonstationary hypotheses in macroeconomic time series", Journal of Econometrics, vol. 80, pp. 241-268. 
Gourieroux, C. and A. Monfort (1997): Time series and dynamic models, Cambridge, Cambridge University Press.

Granger, C. W. J. (1980): "Long memory relationships and the aggregation of dynamic models", Journal of Econometrics, vol. 14, pp. 227-238.

Granger, C. W. J. (1981): "Some properties of time series data and their use in econometric model specification”, Journal of Econometrics, vol. 16, pp. 121-130.

Granger, C. W. J. and R. Joyeux (1980): "An introduction to long memory time series and fractional differencing", Journal of Time Series Analysis, vol. 1, pp. 15-29.

Hadri, K. (2000): "Testing for Stationarity in Heterogeneous Panel Data," Econometric Journal, vol. 3, pp. 148-161.

Hasslers, U., and J. Wolters (1994): On the power of unit root tests against fractional alternatives, Economics Letters, vol. 45, pp. 1-5.

Holmes, M. J. (2004): "Current account deficits in the transition economies", Prague Economic Papers, vol. 4, pp. 347-358.

Holmes, M. J. (2006): "Do Latin American countries have an incentive to default on their external debts? A perspective based on long-run current account behaviour", Emerging Markets Finance and Trade, vol. 42, pp. 33-49.

Holmes, M. J. And T. Panagiotidis (2009): "Cointegration and asymmetric adjustment: Some evidence concerning the behaviour of the US current account", The B. E. Journal of Macroeconomics 9.1.

Hosking, J. R. M. (1981): "Modelling persistence in hydrological time series using fractional differencing", Water Resources Research, vol. 20, pp. 1898-1908.

Husted, S. (1992): "The emerging US current account deficit in the 1980s: A cointegration analysis", Review of Economics and Statistics, vol. 74, pp. 159-166.

Im, K. S., M. H. Pesaran, and Y. Shin (2003): "Testing for unit roots in heterogeneous panels," Journal of Econometrics, vol. 115, pp. 53-74.

Kapetanios, G., Y. Shin and A. Snell (2003): "Testing for a unit root in the nonlinear STAR framework", Journal of Econometrics, vol. 112, pp. 359-379.

Kwiatkowski, D., P. C. B. Phillips, P. Schmidt and Y. Shin (1992). "Testing the Null Hypothesis of Stationary against the Alternative of a Unit Root," Journal of Econometrics, vol. 54, pp. 159178.

Lee, D. and P. Schmidt (1996): "On the power of the KPSS test of stationarity against fractionally integrated alternatives", Journal of Econometrics, vol. 73, pp. 285-302. 
Levin, A., C. F. Lin, and C. Chu (2002): "Unit root tests in panel data: asymptotic and finite-sample properties", Journal of Econometrics, vol. 108, pp. 1-24.

Maddala, G. S. and S. Wu (1999): "A comparative study of unit root tests with panel data and a new simple test", Oxford Bulletin of Economics and Statistics, vol. 61, pp. 631-52.

Mann, C. L. (2002): "Perspectives on the US current account deficit and sustainability", Journal of Economic Perspectives, vol. 16, pp. 131-152.

Milesi-Ferretti, G. M. and A. Razin (1996): "Current-account sustainability", Princeton Studies in International Finance, no. 81, October 1996.

Milesi-Ferretti, G. M. and A. Razin (1998): "Current account reversals and currency crises: Empirical regularities”, NBER Working Paper 6620.

Moulines, E. and P. Soulier (1999): "Broad band log-periodogram estimator of time series with long range dependence”, Annals of Statistics, vol. 27, pp. 1415-1439.

Ng, S. and P. Perron (2001): "Lag selection and the construction of unit root tests with good size and power", Econometrica, vol. 69, pp. 1519-1554.

Pesaran, M. H. (2007): “A simple panel unit root test in the presence of cross section dependence, Journal of Applied Econometrics, vol. 142, pp. 50-93.

Phillips, P. C. B. (1987): "Time series regression with a unit root", Econometrica, vol. 55, pp. 311340.

Phillips, P. C. B. and P. Perron (1988): "Testing for a unit root in time series regression", Biometrica, vol. 75, pp. 335-346.

Phillips, P. C. B. and K. Shimotsu (2002): "Pooled log-periodogram regression", Journal of Time Series Analysis, vol. 23, pp. 57-93.

Robinson, P. M. (1995): "Log-Periodogram Regression of Time Series with Long Range Dependence", Annals of Statistics, vol. 23, pp. 1048-1072.

Roubini, N. and P. Wachtel (1999): "Current-Account Sustainability in Transition Economies" in Balance of Payments, Exchange Rates, and Competitiveness in Transition Economies, Kluwer Academic Publishers, pp. 19-93.

Sollis, R. (2009): "A simple unit root test against asymmetric STAR nonlinearity with an application to real exchange rate in Nordic countries", Economic Modelling, vol. 26, pp. 118125.

Stein, J. L. (2007): "United States current account deficits: A stochastic optimal control analysis", Journal of Banking and Finance, vol. 31, pp. 1321-1350.

Taylor, A. M. (2002): “A century of current account dynamics”, Journal of International Money and Finance, vol. 21, pp. 725-748. 
Trehan, B. and C. Walsh (1991): "Testing intertemporal budget constraints: theory and applications to US federal budget deficits and current account deficits", Journal of Money, Credit and Banking, vol. 26, pp. 206-223.

Velasco, C. (2000): "Non-Gaussian Log-Periodogram Regression”, Econometric Theory, vol 16, pp. 44-79. 
Table 1: Panel tests for the order of integration

\begin{tabular}{lcc}
\hline \hline Test & Raw p-val. & CSD p-val. \\
\hline Levin, Lin and Chu & 0.9758 & 0.7040 \\
Im, Pesaran and Shin & 0.7093 & 0.0666 \\
ADF-Fisher & 0.6651 & 0.4989 \\
PP-Fisher & 0.0003 & 0.0010 \\
Hadri & 0.0778 & 0.0000 \\
\hline \hline
\end{tabular}

Note: p-values are reported. The second column refers to the test with no cross sectional dependence correction, whereas the third column refers to the test applied controlling for cross sectional dependence.

Table 2: Ng-Perron, KSS and Sollis (2009) unit root test results

\begin{tabular}{lcccccc}
\hline \hline & MZa & MZt & MSB & MPT & KSS & Sollis \\
\hline Bulgaria & -2.033 & -0.950 & 0.467 & 11.466 & -0.995 & 0.529 \\
Czech Rep. & $-10.066^{* *}$ & $-2.241^{* *}$ & $0.222^{* *}$ & $2.442^{* *}$ & $-3.614^{* *}$ & $7.088^{* *}(\mathrm{~S})$ \\
Estonia & $-8.453^{* *}$ & $-1.931^{* *}$ & $0.228^{* *}$ & $3.363^{*}$ & -0.828 & 0.783 \\
Hungary & -2.369 & -0.762 & 0.321 & 8.566 & -0.345 & 2.709 \\
Latvia & $-6.270^{*}$ & $-1.737^{*}$ & 0.277 & $4.016^{*}$ & -1.286 & 0.810 \\
Lithuania & -5.725 & -1.499 & 0.261 & 4.832 & $-3.326^{* *}$ & $5.814^{* *}(\mathrm{~S})$ \\
Poland & -2.518 & -1.082 & 0.429 & 9.528 & -1.709 & 3.304 \\
Romania & -5.301 & -1.617 & 0.305 & 4.651 & -1.459 & 2.968 \\
Slovakia & -0.335 & -0.158 & 0.472 & 16.763 & -0.375 & 1.694 \\
Slovenia & -4.521 & -1.485 & 0.328 & 5.453 & -0.568 & 0.526 \\
\hline \hline
\end{tabular}

Note: The order of lag to compute the tests has been chosen using the modified AIC (MAIC) suggested by Ng and Perron (2001). MZa and MZt that are the modified versions of Phillips' (1987) and Phillips and Perron's (1988) Za and Zt tests; the MSB that is related to Bhargava's (1986) R1 test; and, finally, the MPT test that is a modified version of Elliot, Rothenberg and Stock's (1996) Point Optimal Test. The Ng-Perron tests include an intercept, whereas the KSS test has been applied to the de-meaned data. The symbols * and ** mean rejection of the null hypothesis at the $10 \%$ and $5 \%$ significance levels respectively. (S) stands for symmetric adjustment. The critical values for the Ng-Perron tests and F-test have been taken from Ng and Perron (2001) and Sollis (2009) respectively, whereas those for the KSS have been obtained by Monte Carlo simulations with 50,000 replications.

Critical Values

\begin{tabular}{lcccccc}
\hline & MZa & MZt & MSB & MPT & KSS & Sollis \\
\hline $5 \%$ & -8.100 & -1.980 & 0.233 & 3.170 & -2.886 & 4.886 \\
\hline $10 \%$ & -5.700 & -1.620 & 0.275 & 4.450 & -2.603 & 4.009 \\
\hline
\end{tabular}


Table 3: Robinson's (1995) test. Pooled estimation

\begin{tabular}{ccccc}
\hline Country & Est. $d$ & $\begin{array}{c}\text { Std. } \\
\text { Error }\end{array}$ & t-statistic & p-value \\
\hline Bulgaria & 0.570 & 0.128 & 4.446 & 0.000 \\
Czech Rep. & 0.317 & 0.128 & 2.472 & 0.018 \\
Estonia & 0.477 & 0.128 & 3.716 & 0.001 \\
Hungary & 0.644 & 0.128 & 5.017 & 0.000 \\
Latvia & 0.889 & 0.128 & 6.928 & 0.000 \\
Lithuania & 0.625 & 0.128 & 4.871 & 0.000 \\
Poland & 0.725 & 0.128 & 5.650 & 0.000 \\
Romania & 0.671 & 0.128 & 5.227 & 0.000 \\
Slovakia & 0.289 & 0.128 & 2.254 & 0.030 \\
Slovenia & 0.437 & 0.128 & 3.409 & 0.002 \\
\hline \hline
\end{tabular}

Note: As suggested by Robinson (1995), the test has been applied using 0.9 as power for the number of ordinates entering the log-periodogram regression.

Table 4: ARFIMA estimation

\begin{tabular}{cccccc}
\hline \hline Country & $\mathrm{AR}(1)$ & $\mathrm{AR}(2)$ & $\mathrm{AR}(3)$ & $\mathrm{AR}(4)$ & Estimated $d$ \\
\hline Bulgaria & -0.018 & 0.442 & 0.269 & 0.012 & 0.658 \\
Czech Rep. & -0.285 & 0.071 & 0.134 & 0.104 & 0.742 \\
Estonia & 0.067 & 0.565 & 0.215 & -0.105 & 0.493 \\
Hungary & -0.108 & -0.091 & -0.118 & 0.167 & 0.981 \\
Latvia & 0.553 & 0.131 & 0.197 & -0.253 & 0.606 \\
Lithuania & 0.115 & 0.425 & 0.008 & -0.237 & 0.720 \\
Poland & 0.256 & - & - & - & 0.707 \\
Romania & -0.212 & -0.044 & 0.019 & -0.267 & 1.140 \\
Slovakia & -0.298 & -0.185 & -0.003 & -0.192 & 0.850 \\
Slovenia & 0.267 & 0.049 & 0.372 & -0.115 & 0.302 \\
\hline \hline
\end{tabular}


Figure 1: Current account ratio to GDP
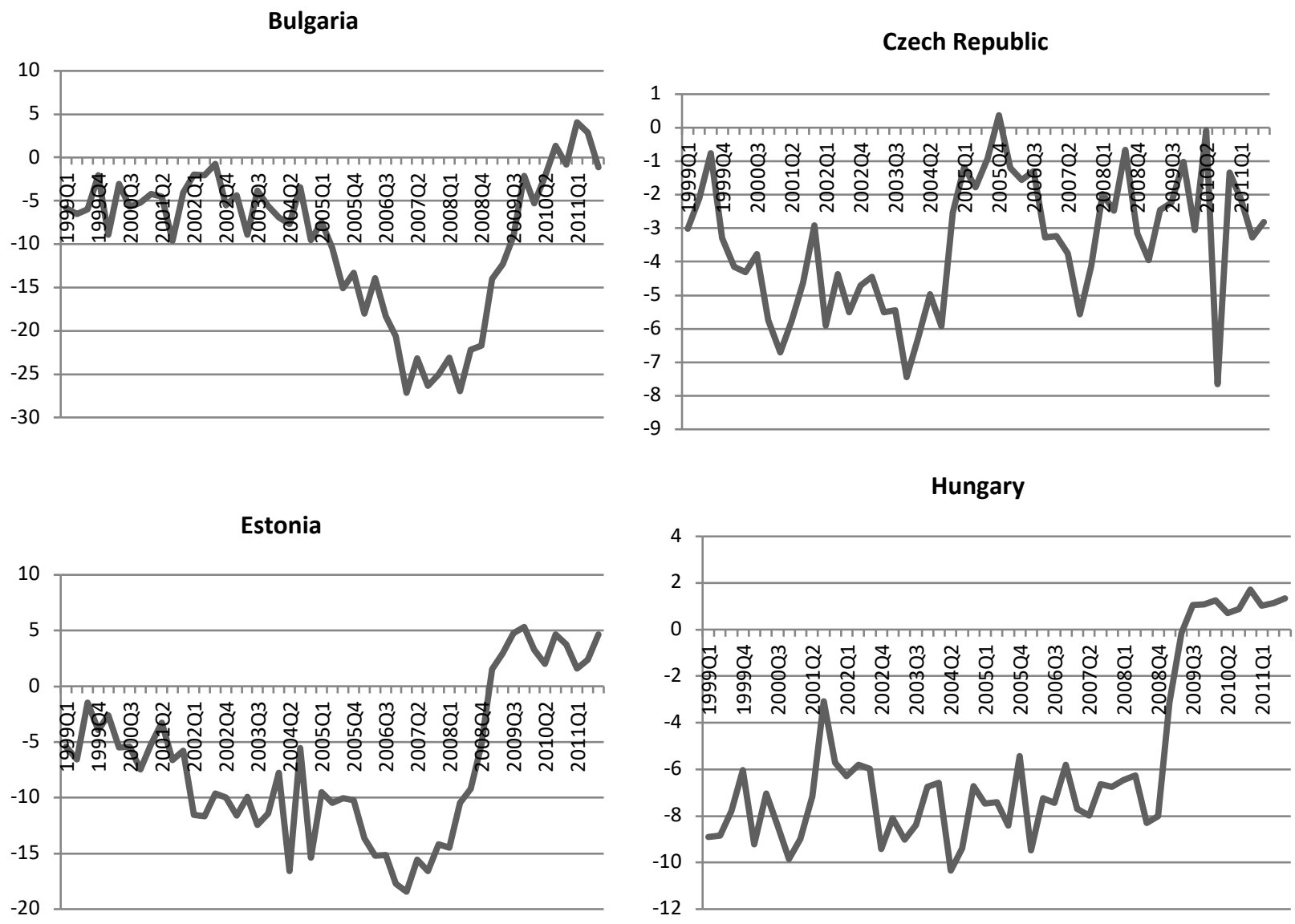

Latvia

Lithuania
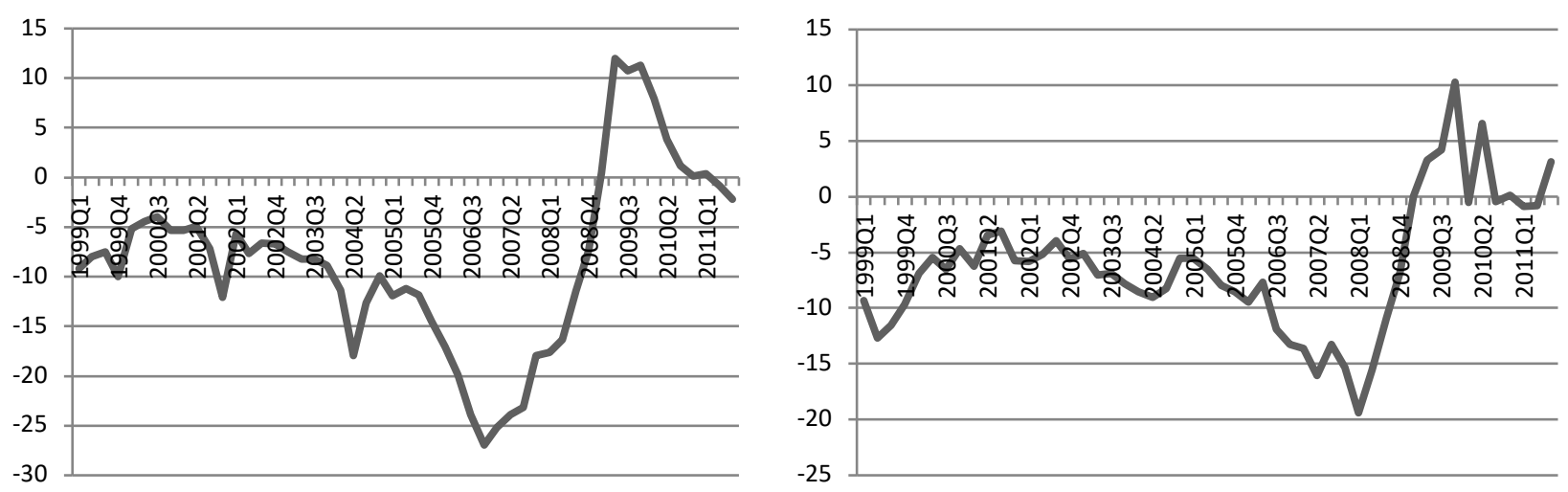

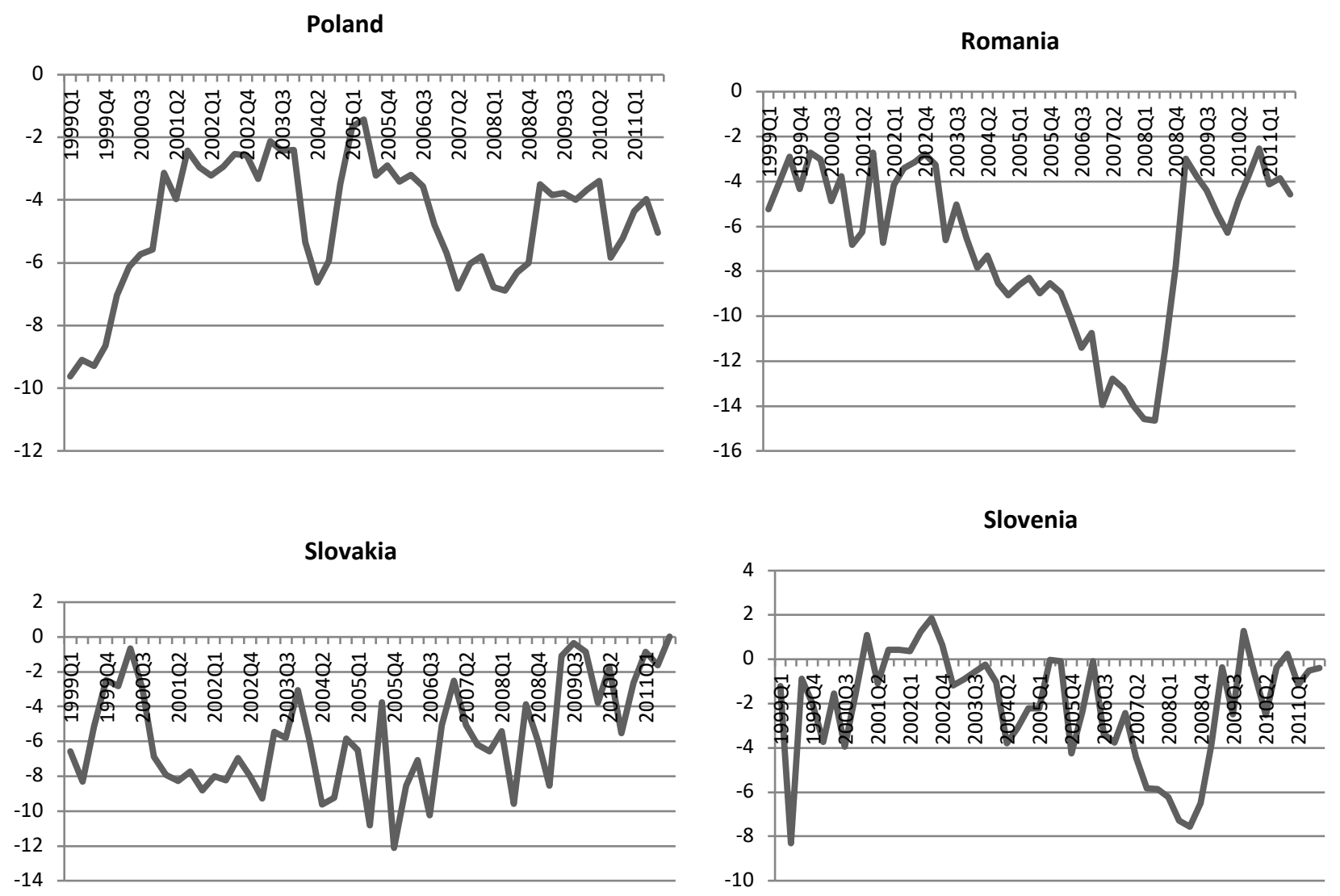
Figure 2: Impulse-response functions

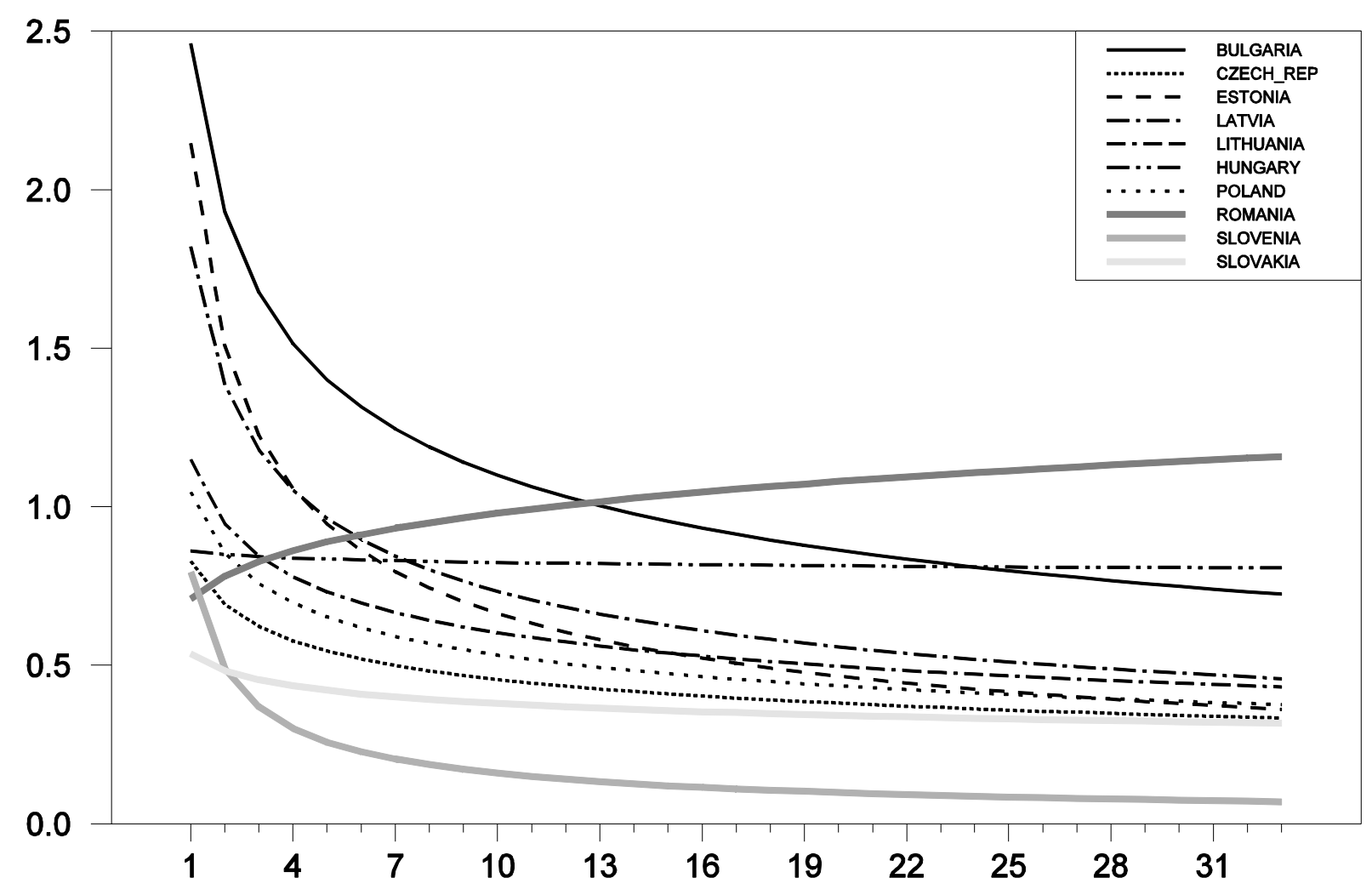

